\title{
Inhibition of return, gap effect and saccadic reaction time to a visual target
}

S. Guimarães-Silva,

L.G. Gawryszewski,

T.S. Portugal and

L. Klausner-de-O liveira
Departamento de Neurobiologia, Universidade Federal Fluminense, Niteroi, RJ, Brasil

\section{Correspondence \\ L.G. Gawryszewski \\ Departamento de Neurobiologia, UFF \\ Caixa Postal 100.180 \\ 24001-970 Niteroi, RJ \\ Brasil \\ E-mail: gnelggw@vm.uff.br}

Presented at the XVIII Annual M eeting of the Federação de Sociedades de Biologia Experimental, Curitiba, PR, Brazil, August 27-30, 2003.

Research supported by $\mathrm{CNPq}$, PRO NEX/MCT, CAPES, PIBIC, FAPERJ and UFF. This study is part of a Master's thesis presented by S. Guimarães-Silva to the Programa de Neuroimunologia, UFF, Niteroi, RJ, Brazil.

\section{Abstract}

Simple manual reaction time (MRT) to a visual target (S2) is shortened when a non-informative cue (S1) is flashed at the S2 location shortly before the onset of S2 (early facilitation). Afterwards, MRT to S2 appearing at the $\mathrm{S} 1$ location is lengthened (inhibition of return - IOR). Similar results have been obtained for saccadic reaction time (SRT). Moreover, when there is a temporal gap between offset of the fixation point (FP) and onset of a target (gap paradigm), SRT is shorter than SRT in an overlap paradigm (FP remains on). In the present study, we determined SRT to S2 $\left(10^{\circ}\right)$ after presenting S1 at the same eccentricity $\left(10^{\circ}\right)$ or at a parafoveal position $\left(2^{\circ}\right)$ in the same or in the opposite hemifield. In addition, we employed both gap and overlap paradigms. Twelve subjects were asked not to respond to $\mathrm{S} 1\left(2^{\circ}\right.$ or $\left.10^{\circ}\right)$ to the right or to the left of FP, but to respond by making a saccadic movement in response to S2. We obtained the following results: 1) a 40-ms gap effect, 2) an interaction between gap effect and IOR, 3) a 39-ms delay (IOR) when S2 appeared at the cued (S1) position, and 4) a smaller (17 $\mathrm{ms}$ ) but significant inhibition when $\mathrm{S} 1$ occurred at $2^{\circ}$ in the ipsilateral hemifield. Thus, a parafoveal $\left(2^{\circ}\right)$ S1 elicits an inhibition of SRT towards ipsilateral peripheral targets. Since an inhibition of the ipsilateral hemifield by a $1^{\circ}$ eccentric cue has been reported to occur when manual responses are employed, we suggest that the postulated functional link between covert and overt orienting of attention is also valid for parafoveal cues.

Manual reaction time (MRT) to a peripheral visual target is shortened when a noninformative cue is flashed at the target location 100-150 ms before the target onset (early facilitation). Afterwards, MRT to targets appearing at the cue position is lengthened (inhibition of return - IOR) (1). The spatial distribution of IOR is one of its conspicuous properties. Several investigators have found

\section{Key words}

- Visual attention

- Saccadic reaction time

- Inhibition of return

- Covert orienting

- Gap effect that IOR is maximal at cue position, but the inhibition spreads over a large extension of the ipsilateral hemifield (2-8). For instance, Berlucchi et al. (2) have reported that a cue located at $1^{\circ}$ from the fixation point (FP) inhibits the manual response to an ipsilateral target located at a $30^{\circ}$ eccentric position (a $29^{\circ}$ cue-target distance), but does not inhibit the response to a contralateral target located 
at $1^{\circ}$ from the FP (a $2^{\circ}$ cue-target distance). These findings are symmetrical with those found in covert voluntary orienting of attention experiments in which the MRT to a target occurring at the attended point is shorter than to targets occurring at other positions (9-11). Moreover, the benefit arising from the orienting of attention decreases with distance between the attended position and target position but does not cross the meridians $(3,12)$. To explain the difference between attended and unattended positions, Rizzolatti and colleagues (11) proposed that the motor programs for eye movement control both overt and covert orienting of attention, so that, "to pay attention" to a peripheral position corresponds to programming an eye movement that will direct the eyes to the attended position if the eye movements are not blocked voluntarily (premotor theory of visual attention). Moreover, the program specifies the direction of eye movement and the exact amplitude to be covered. So, when the stimulus occurs at the attended position, an ocular or manual response will be emitted without further delay. However, when the stimulus occurs at an unexpected position, a time-consuming change in the ocular program is required, involving a cost whose magnitude depends on the movement feature that must be modified. The cost will be greater if the attended and stimulus positions are located on opposite sides of the vertical or horizontal meridian and will be smaller if they are located at different positions inside the same hemifield. On the other hand, the inhibitory effect of a non-informative cue may arise from the veto of overt responses (eye movement) towards the cue, delaying all responses to targets located in the cue hemifield $(3,4)$.

Similar effects of voluntary orienting of attention on saccadic eye movements have also been observed (13). Moreover, inhibition has been found for saccadic eye reaction time when the visual target is presented at the same position as the cue $(8,14,15)$ or in another peripheral position in the same hemifield $(12,14,15)$. In short, the covert voluntary orienting of attention elicits maximal facilitation at the attended position and from there a decreasing facilitation in the ipsilateral hemifield which stops at the main meridians. On the other hand, a non-informative cue elicits an inhibition that follows similar but opposite spatial distribution rules (maximal inhibition at a cue position which decreases with distance and stops at the main meridians) (2-4).

For saccadic reaction time (SRT), it has also been reported that introducing a temporal gap between the offset of the FP and the onset of a peripheral target (gap paradigm) shortens the latency of saccadic eye movements (gap effect) in comparison to a condition in which FP remains on (overlap paradigm) (16). Moreover, Abrams and Dobkin (17) have reported that the magnitude of the gap effect for saccades is greater in the noncued hemifield ( $34 \mathrm{~ms}$ - experiment 2, $36 \mathrm{~ms}$ - experiment 3) than in the previously attended location ( $28 \mathrm{~ms}$ - experiment $2,19 \mathrm{~ms}$ - experiment 3). However, this result may be due to the difference in IOR between the overlap and gap conditions. Indeed, the cited investigators found a small IOR $(4 \mathrm{~ms}$ in experiment 2 , and $2 \mathrm{~ms}$ in experiment 3 ) in the overlap condition and a larger IOR (10 $\mathrm{ms}$ in experiment 2 and $19 \mathrm{~ms}$ in experiment 3 ) in the gap condition. Although there are no definitive data excluding the possibility that IOR could be due to a facilitation of the contralateral hemifield, the dominant view is that IOR is a phenomenon which involves inhibition of the ipsilateral hemifield. According to this view, Abrams and Dobkin's results should be interpreted as a reduction of the gap effect in the cued location due to the presence of IOR.

Many studies have suggested that the superior colliculus (SC) is involved in covert and overt orienting of attention as well as in the gap effect (for reviews, see Refs. 18 and 19). However, the SC might not be sufficient 
for IOR to be observed (19). Single-unit recording has shown that when the target was presented at a previously cued location the response of collicular neurons was attenuated and the magnitude of this response was correlated with subsequent SRT. However, this reduction in collicular activity was not caused by active inhibition of these neurons due to the cue. Indeed, the neuronal activity increases after the presentation of the cue in its response field and the electrical microstimulation of the SC elicits faster saccades when the cued location is stimulated. This implies that the primate SC participates in the expression of IOR. However, the SC is not the site of inhibition. Instead, the reduced response of collicular neurons reflects a signal reduction elicited by the cue that has occurred upstream, probably in the posterior parietal cortex (19).

The present investigation addresses two questions related to the mechanisms involved in covert and overt orienting of attention as well as in ocular fixation and eye movements. The first one is if there is an interaction between the gap effect and the inhibition of return. The second one is if a parafoveal $\left(2^{\circ}\right)$ cue which is represented in the fixation region in the rostral pole of the SC lengthens the SRT to an ipsilateral peripheral $\left(10^{\circ}\right)$ target.

Twelve right-handed young adults (2 males and 10 females) with normal or corrected visual acuity volunteered to take part in the experiment. All were naive in reaction time tasks and were unaware of the purpose of the experiment. The experiment took place in a sound-attenuated dark room. The subject sat in front of a screen to which green light-emitting diodes were attached. A Pentium microcomputer timed the stimuli and recorded the responses (saccadic movements). We used an infrared scleral reflectance device (Applied Science Laboratories, model 210, Bedford, MA, USA) to record eye movements. Recorded data were sent to a personal computer for storage and analysis using National Instruments cards (Lab-PC+ and AT-AO-6) and software (Austin, TX, USA). A velocity criterion of $30 \%$ was employed to define the beginning of the ocular saccade. The head was positioned on a headand-chin rest so that the distance between the eyes and the screen was maintained at 57 $\mathrm{cm}$. Each subject participated in 5 experimental sessions on separate days or, sometimes, on the same day separated by a rest of at least $1 \mathrm{~h}$.

A session consisted of 320 trials divided into 4 blocks separated by rest periods of a few minutes. The blocks differed according to $\mathrm{S} 1$ eccentricity $\left(2\right.$ or $10^{\circ}$ ) and fixation condition (gap or overlap). Each trial began with the presentation of an FP in the center of the screen (Figure 1). Nine hundred milliseconds later, a non-informative cue (S1) appeared at $2^{\circ}\left(\right.$ or $\left.10^{\circ}\right)$ to the right or the left of the FP and remained on for $100 \mathrm{~ms}$. Seven



Figure 1. Schematic diagram and temporal sequence of events during trials. A, Relative positions of the fixation point (FP) when the cue occurred: $1,10^{\circ}$ on the left and the target was presented $10^{\circ}$ on the right (cue and target in opposite hemifields), $2,2^{\circ}$ on the left and the target was presented $10^{\circ}$ on the right (cue and target in opposite hemifields), $3,10^{\circ}$ on the right and the target was presented $10^{\circ}$ on the right (cue and target at the same position), $4,2^{\circ}$ on the right and the target was presented $10^{\circ}$ at right (cue and target in the same hemifield, but in different locations). B, Temporal sequence of events: the overlap paradigm in which the FP remains on throughout the trial is illustrated on the left and the gap paradigm in which the FP is turned off $200 \mathrm{~ms}$ before the appearance of the target is illustrated on the right. 
hundred milliseconds after its offset, a target (S2) was flashed for $100 \mathrm{~ms} 10^{\circ}$ to the right or to the left of the FP. The interval between the onset of S1 and of S2 (stimulus onset asynchrony) was $800 \mathrm{~ms}$. In the overlap paradigm, the FP was on when the target appeared and remained on until the end of trial. In the gap paradigm, the FP was offset $200 \mathrm{~ms}$ before the appearance of the target. The subjects were instructed to look at FP, not to respond to $\mathrm{S} 1$ and to respond as quickly as possible to the onset of $\mathrm{S} 2$ by making a target-directed saccade. SRT was measured from the onset of $\mathrm{S} 2$ to the beginning of the saccade. SRT shorter than $80 \mathrm{~ms}$ or longer than $699 \mathrm{~ms}$ were considered to be errors and these trials were not included in the analyses. The first session was used for practice and its data were discarded. The data of the additional 4 sessions were pooled. At the end of these sessions, 16 correct mean SRT values were calculated for each subject. These means were entered into a four-way repeated measure analysis of variance (ANOVA) with the following factors: fixation condition (overlap or gap), $\mathrm{S} 1$ eccentricity $\left(2^{\circ}\right.$ or $\left.10^{\circ}\right)$, S2 hemifield (left or right), S1-S2 spatial relation (ipsi- or contralateral condition). The pairwise comparisons described below were made using the Newman-Keuls method and the level of significance was always set at $\mathrm{P}<0.05$.

Figure 2. Saccadic reaction time (SRT) to targets presented in the same (IPSI) or in the opposite hemifield (OP) of the cue. The cue appeared at $2^{\circ}$ or $10^{\circ}$ from the fixation point and the target always appeared at $10^{\circ}$ from the fixation point. There was a significant difference between the SRT observed when cue and target appeared at the same position (IPSI_10 $10^{\circ}$ and all other SRT. There was also a significant difference between the SRT ob-

served when the cue appeared at $2^{\circ}$ in the opposite hemifield (OP_ $2^{\circ}$ ) and at $2^{\circ}$ in ipsilateral hemifield (IPSI $\left.2^{\circ}\right)$. On the other hand, there was no significant difference between the conditions in which the cue appeared at $2^{\circ}$ or $10^{\circ}$ in the contralateral hemifield. Pairwise comparisons were made with the Newman-Keuls test $(P<0.05)$.
Three main factors had significant effects on reaction time: fixation condition, S1-S2 spatial relation and S1 eccentricity. SRT was longer $(207 \mathrm{~ms})$ in the overlap condition $(\mathrm{F}(1,11)=30.122, \mathrm{P}=0.000)$ than in the gap condition (167 ms). When S2 appeared in the cued hemifield, SRT (201 $\mathrm{ms})$ was longer $(\mathrm{F}(1,11)=70.000, \mathrm{P}=0.000)$ than when S1 and S2 occurred in opposite hemifields (173 ms). Finally, when S1 occurred at a peripheral $\left(10^{\circ}\right)$ position, SRT $(196 \mathrm{~ms})$ was longer $(\mathrm{F}(1,11)=23.884, \mathrm{P}=$ $0.000)$ than when $\mathrm{S} 1$ occurred at a parafoveal $\left(2^{\circ}\right)$ location $(178 \mathrm{~ms})$.

In addition, there were two significant interactions. The first was between the fixation condition and the S1-S2 spatial relation$\operatorname{ship}(F(1,11)=9.797, P=0.010)$. For the gap paradigm, SRT in the ipsilateral hemifield (184 ms) was longer than SRT in the contralateral hemifield $(151 \mathrm{~ms}, \mathrm{IOR}=33 \mathrm{~ms})$. For the overlap paradigm, SRT in the ipsilateral hemifield $(219 \mathrm{~ms})$ was also longer than SRT in the contralateral hemifield (195 ms), but IOR (24 ms) was smaller than in the gap paradigm. The gap effect for ipsilateral and contralateral targets was found to be greater when the target and the cue occurred in opposite hemifields (44 ms) than when they occurred in the same hemifield $(33 \mathrm{~ms})$, confirming data reported by Abrams and Dobkin (17). The second significant interaction was between the S1-S2 spatial relationship and $\mathrm{S} 1$ eccentricity $(\mathrm{F}(1,11)=16.848, \mathrm{P}$ $=0.002$ ) and is illustrated in Figure 2 .

SRT obtained when S2 occurred at the S1 position (SRT $=216 \mathrm{~ms}$ ) was $39 \mathrm{~ms}$ longer than when $\mathrm{S} 1$ and $\mathrm{S} 2$ occurred at $10^{\circ}$ in opposite hemifields ( $177 \mathrm{~ms}, \mathrm{IOR}=39 \mathrm{~ms}$ ). A smaller $(17 \mathrm{~ms})$ but significant inhibition was elicited when the $S 1$ appeared at $2^{\circ}$ from the FP in the ipsilateral hemifield. The SRT (187 ms) when a parafoveal $\left(2^{\circ}\right) \mathrm{S} 1$ occurred before a peripheral $\left(10^{\circ}\right) \mathrm{S} 2$ in the same hemifield was longer $(\mathrm{P}>0.05)$ than the SRT observed when a parafoveal S1 and a peripheral S2 occurred in opposite hemifields 
(170 ms). On the other hand, there was no significant difference $(\mathrm{P}>0.05)$ between the conditions in which $\mathrm{S} 1$ appeared at $2^{\circ}$ or $10^{\circ}$ in the contralateral hemifield (170 and 177 ms, respectively).

Five general results are striking: a) when the FP was kept on (overlap-paradigm), SRT (207 ms) was longer than when the FP was turned off $200 \mathrm{~ms}$ before the target stimulus appeared (gap-paradigm, SRT $=167 \mathrm{~ms}$ ), a 40-ms gap effect; b) the gap effect was greater when the target and the cue occurred in opposite hemifields ( $44 \mathrm{~ms}$ ) than when they occurred in the same hemifield (33 ms); c) the IOR was greater in the gap paradigm (33 $\mathrm{ms})$ than in the overlap paradigm $(24 \mathrm{~ms})$; $)$ $\mathrm{S} 1$ elicited a 39-ms delay (IOR) if it occurred at the $\mathrm{S} 2$ position, and e) a smaller (17 $\mathrm{ms})$ but significant inhibition was elicited when the $\mathrm{S} 1$ appeared at $2^{\circ}$ from the FP in the ipsilateral hemifield.

As described before, IOR was discovered using manual responses and covert orienting of the attention paradigm (1). Since then, several investigators have described the spatial distribution of the inhibitory effects of a non-informative cue on manual and ocular responses to a visual target $(2,3$, $5,7,8,11,14,15)$. Usually, there is no discrepancy between the results found using covert (without eye movements) and overt (with eye movements) responses, in agreement with the premotor theory of attention (11). However, until know, the non-informative cue in IOR ocular studies was always presented at an eccentric position, that is, outside the fixation region which is represented by the rostral pole of the SC (for reviews, see Refs. 19 and 20). The role of the rostral colliculus in eye fixation and the reciprocal inhibitory connection between the fixation region and the saccadic region in the caudal colliculus (for a review, see Ref. 20) may elicit a dissociation between the IOR for manual responses and the IOR for ocular response. However, our results show that a parafoveal $\left(2^{\circ}\right)$ cue elicited an inhibition of the saccades directed towards peripheral positions in the ipsilateral hemifield that was similar to the inhibition elicited by a $1^{\circ}$ eccentric cue on manual responses to targets occurring over a large extension of the ipsilateral hemifield (2). These results suggest that a parafoveal cue has similar effects on covert and overt orientation of attention.

Our main result is that a parafoveal $\left(2^{\circ}\right)$ non-informative cue elicits an inhibition of saccadic eye movements towards an ipsilateral peripheral $\left(10^{\circ}\right)$ target, as observed for manual responses (2). This is an unexpected result because the rostral colliculus is involved in ocular fixation (20). However, a recent electrophysiological study (19) has shown that the primate SC participates in the expression of IOR, but is not the site of inhibition. Instead, the reduced response of collicular neurons reflects a signal reduction elicited by the cue that has occurred upstream, probably in the posterior parietal cortex (19). The possible participation of cortical structures in IOR may explain the similarities between the ocular and manual expression of IOR.

\section{Acknowledgments}

We thank Dr. Paulo dos Santos Rodrigues (Departamento de Neurobiologia, Universidade Federal Fluminense, Brazil), Prof. John M. Findlay (Department of Psychology, University of Durham, UK), Prof. Robert D. Rafal (School of Psychology, University of Wales, UK) and Dr. Antônio Pereira Jr. (Departamento de Fisiologia, Universidade Federal do Pará, Brazil) for their valuable comments on an earlier version of the manuscript. 


\section{References}

1. Posner MI \& Cohen $Y$ (1984). Components of visual orienting. In: Bouma $\mathrm{H} \&$ Bouwhuis GG (Editors), Attention and Performance. $\mathrm{X}$. Erlbaum, Hillsdale, NJ , USA, 531-556.

2. Berlucchi G, Tassinari G, Marzi CA \& Di Stefano M (1989). Spatial distribution of the inhibitory effect of peripheral non-informative cues on simple reaction time to non-fixated visual targets. Neuropsychologia, 27: 201-221.

3. Tassinari G, Aglioti S, Chelazzi L, Marzi CA \& Berlucchi G (1987). Distribution in the visual field of the costs of voluntarily allocated attention and the inhibitory after-effects of covert orienting. Neuropsychologia, 25: 55-71.

4. Tassinari G \& Berlucchi G (1995). Covert orienting to non-informative cues: reaction time studies. Behavioural Brain Research, 71: 101-112.

5. Gawryszewski LG, Thomaz TG, Machado-Pinheiro W \& Carreiro LRR (1994). Spatial distribution of the inhibition elicited by the offset of a visual cue on manual reaction times to a visual target. Brazilian J ournal of Medical and Biological Research, 27: 67-73.

6. Gawryszewski LG, Carreiro LRR \& Magalhães FV (2002). Cue inhibitory effects on manual response to a visual target: Are they based on Cartesian coordinates? In: Fechner Day 2002 - Eighteenth Annual Meeting of the International Society for Psychophysics, 18 : 363-368.

7. Maylor EA \& Hockey R (1985). Inhibitory component of extemally controlled covert orienting in visual space. J oumal of Experimental Psychology: Human Perception and Performance, 11: 777-787.

8. Maylor EA (1985). Facilitatory and inhibitory components of orienting in visual space. In: Posner MI \& Marin OSM (Editors), Attention and Performance. XI. Erlbaum, Hillsdale, NJ, USA, 189-204.

9. Posner MI (1978). Chronometric Explorations of the Mind. Lawrence Erlbaum Associates, Hillsdale, NJ, USA.

10. Gawryszewski LG, Riggio L, Rizzolatti G \& Umiltà C (1987). Move- ments of attention in the three spatial dimensions and the meaning of 'neutral' cues. Neuropsychologia, 25: 19-29.

11. Rizzolatti G, Riggio L, Dascola I \& Umiltá C (1987). Reorienting attention across the horizontal and vertical meridians: Evidence in favor of a premotor theory of attention. Neuropsychologia, 25: 3140.

12. Gawryzewski LG \& Carreiro LRR (1996). Interaction between facilitatory and inhibitory effects due to voluntary and automatic covert orienting of attention. Revista Brasileira de Biologia, 2: 281-291.

13. Walker R, Kentridge RW \& Findlay J M (1995). Independent contributions of the orienting of attention, fixation offset and bilateral stimulation on human saccadic latencies. Experimental Brain Research, 103: 294-310.

14. Posner MI, Rafal RD, Choate LS \& Vaughan J (1985). Inhibition of retum: neural basis and function. Cognitive Neuropsychology, 2: 211-228.

15. Ro T, Pratt J \& Rafal RD (2000). Inhibition of return in saccadic eye movements. Experimental Brain Research, 130: 264-680.

16. Saslow MG (1967). Latency for saccadic eye movement. J oumal of the Optical Society of America, 57: 1030-1033.

17. Abrams RA \& Dobkin RS (1994). The gap effect and inhibition of retum: interactive effects on eye movement latencies. Experimental Brain Research, 98: 483-487.

18. Fischer $B \&$ Weber $H$ (1993). Express saccades and visual attention. Behavioral and Brain Sciences, 16: 553-610.

19. Dorris MC, Klein MR, Everling S \& Munoz DP (2002). Contributions of the primate superior colliculus to inhibition of return. J oumal of Cognitive Neuroscience, 14: 1-8.

20. Findlay J M \& Walker R (1999). A model of saccade generation based on parallel processing and competitive inhibition. Behavioral and Brain Sciences, 22: 661-721. 